\title{
Impact of Irrigation on Pedologic and Physical Conditions of Farm Soils
}

\author{
Tatarintsev L.M. \\ Altai State Agrarian University \\ Barnaul, Russian Federation \\ e-mail kafzem@bk.ru
}

\author{
Tatarintsev V.L. \\ Altai State Agrarian University \\ Barnaul, Russian Federation \\ e-mail kafzem@bk.ru
}

\author{
Myagkiy P.A. \\ Altai State Agrarian University \\ Barnaul, Russian Federation \\ e-mail kafzem@bk.ru
}

\begin{abstract}
The work was carried out on Novotroitsk irrigation massif located in dry steppe zone of Al-tai Krai. The paper studies the impact of long-term irrigation (10-15 years) by water from $\mathrm{Ob}$ River fed via Kulunda main canal on the parameters of ameliorative condition of chestnut soils. The re-sults discover the direction of soil formation process, determines the degree of alteration of physical, chemical parameters of ameliorative condition depending on the irrigation duration and granulometric composition of the soil. It was unveiled that the irrigation by hydrocarbonate water with the mineralization less than $0.3 \mathrm{~g} / \mathrm{l}$ gives rise to the processes of solodization-leaching. Water converts humus into labile form that migrates into the soil body. Irrigation causes the pedologic and physical conditions to become less favorable for agricultural crops: it increases the number of microaggre-gates, waterproof aggregates larger than $0.25 \mathrm{~mm}$, and raises their mechanical strength and water resistance, increases the soil density, reduces total porosity and water capacity, increases holard and chresard, reduces water permeability indicating the degradation processes in irrigated farm soils.
\end{abstract}

Keywords-Altai Krai, dry steppe zone, irrigation, pedologic and physical conditions, ameliorative condition, granulometric composition, physical properties of farm soils

\section{INTRODUCTION}

An appreciable territory of Altai Krai is a risk farming zone in terms of climate conditions with deficit precipitation during vegetation period. Agrotechnical methods cannot provide substan-tial improvement of water supply to agricultural crops. In this connection, irrigation is one of im-portant factors increasing the stability of yield of feeding and vegetable crops. As of today, there are few to none farms that reach the calculated and designed efficiency of irrigation amelioration. Subsequently, soil looses its natural fertility obtaining a range of negative properties.
A particular attention is drawn by such sites as Novotroitsk irrigation massif that was created to evaluate the productivity of agricultural crops upon irrigation in the conditions of dry steppe zone of Altai Krai, to check and practice a complex of hydroeconomic and agrotechnical measures providing conditions for normal development of plants and high crop yield. The irrigation on the massif was performed with different crop rotation from 10 to 15 years. Thus, the authors have stated the goal to assess the changes to pedologic and physical properties of the irrigated plot..

\section{LITERATURE REVIEW}

Many works are devoted to the study of physical and hydrophysical properties of irrigated farm soils [1-14]. A large number of researchers confirm the negative impact of irrigation on physi-cal and hydrophysical properties; in particular, it appreciably decreases the porosity, content of wa-ter-resistant aggregates, increases the density, water retaining capacity, water resistance of the ag-gregates. The reviewed literature witnesses the existence of rather ambiguous results on the impact of irrigation on pedologic and physical conditions. The reasons of such ambiguity can be explained by a number of factors: initial properties of soils, different quality of irrigation water, cultivated crops, zonal peculiarities of soils and other.

\section{INVESTIGATION METHODOLOGY}

The methodological basis of the studies is systematic approach. The investigation used com-parative geographical and comparative analytical methods. The methods of variation statistics were used to identify the zonal peculiarities and factors of spacial variability of the granulometric compo-sition, determine the boundaries and variation degree of the content of separate fractions of me-chanical elements or elementary soil particles. 


\section{PRACTICAL SignifiCANCE AND RESUlts}

Let us consider the results of our studies carried out on Novotroitsk irrigation massif. The granulometric composition of irrigated soil is one of the main characteristics determining the pedo-logic and ameliorative conditions. On the irrigation massif, the most common are sandy clay loam chestnut soils, less common are sandy loam soils. The granulometric composition turns out to be a stable indicator for irrigated soils. Similarly to non-irrigated chestnut soils, irrigated soils are illuviat-ed in terms of content of silt and physical clay (Fig. 1). Further, the plow horizon of sandy loam irri-gated soils contains less silt fraction as compared to non-irrigated ones by $1-2 \%$; for sandy clay loam soils the difference is $3-5 \%$.

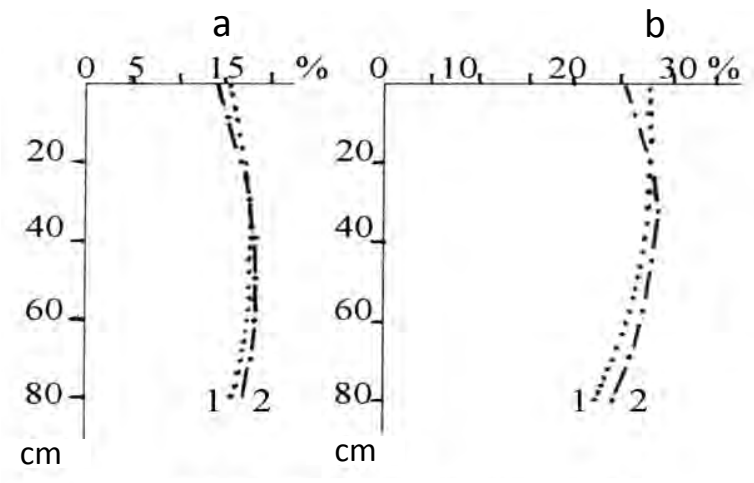

Sand loam soils

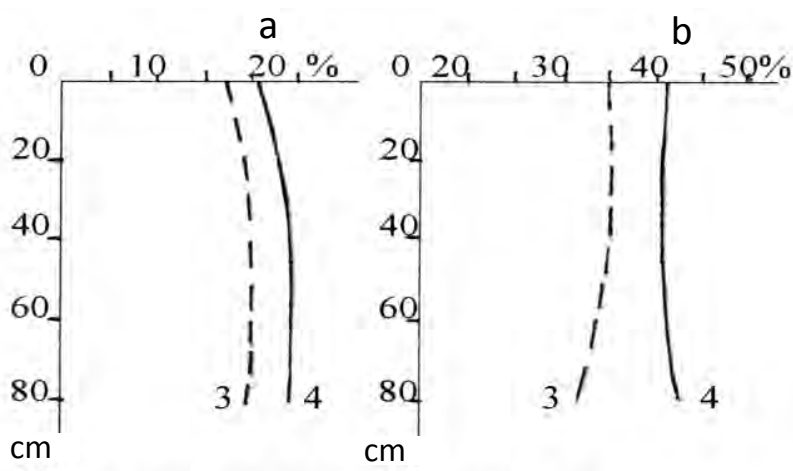

Sand clay loam soils

Fig. 1. Depthwise distribution of silt fraction a) and physical clay (b) in chestnut irrigated silt and sand soils (1), coarse-dust sand soils (2, 3), sand coarse-dust soils (4)

For instance, the irrigation of chestnut soils of sand loam type lead to appreciably changed granulometry. In both siltsand and coarse-dust sand soils (negligibly though), the number of sand fractions $(1-0.05 \mathrm{~mm})$ and silt (less than $0.001 \mathrm{~mm}$ ) rose. Simultaneously, the content of medium and fine dust and physical clay dropped. The irrigated sand clay loam coarse-dust sand soils preserve the same regularity as for sand loam ones. The sand clay loam sand coarse-dust soils demonstrate another trend. In this case, conversely, the content of physical clay has increased with the background of insignificant reduction of the number of sand fractions.

The irrigation of sand clay loam coarse-dust sand soils (Fig. 2 ) increases relative number of groups with high sand content.
In sand coarse-dust soils this elevation is due to the groups with low sand content. In this connection, in coarse-dust sand soils, the arithmetic mean content of sand fractions increased; in sand coarse-dust ones it conversely dropped. Relative number of groups in terms of content of coarse dust remained the same. In coarse-dust sand soils the relative number of groups in terms of medium and fine dust suffered no change, while in sand coarsedust soils the relative number of groups with high $(18-24 \%)$ content of mentioned dust fractions has risen. The probability of values in terms of silt fraction content remained the same, which is confirmed by the equality of average values of silt content.

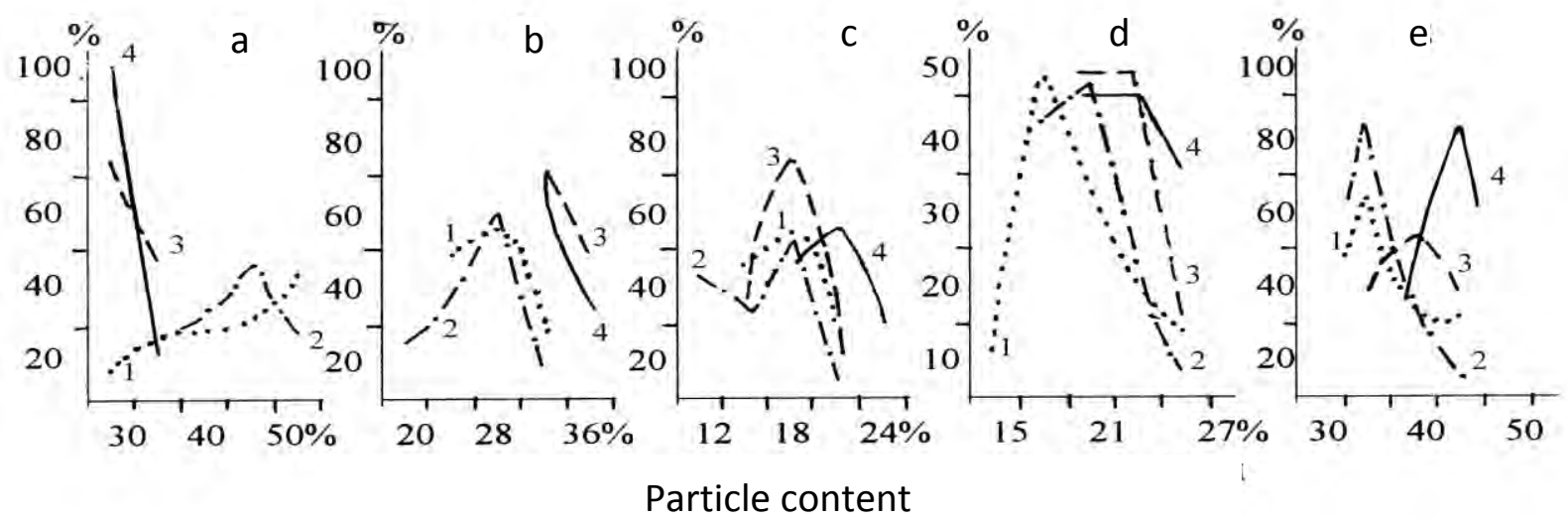

Fig. 2. Relative number of separate groups of sand fraction content a), coarse dust b), medium and fine dust c), silt d) and physical clay e) in chestnut sand clay loam coarse-dust sand soils $(1,2)$ and sand coarse-dust soils $(3,4): 1,3$ are non-irrigated, 2,4 are irrigated

Thus, the irrigation has ambivalent impact on the granulometric composition. According to the losses of silt in plow layer of irrigated sand clay loam soils, the illuviation in them is more intense, as compared to sand loam ones. In sand loam soils, the increased content of silt particles is accompanied by the number of particles with the size of less than $0.01 \mathrm{~mm}$. 
More remarkable loss of physical clay is noted for silt sand soils. in coarse-dust sandy soils of sand clay loam type, the loss of physical clay occurs due to all fractions having the size of less than $0.01 \mathrm{~mm}$. Simultaneously, in sand coarse-dust soils, the total amount of physical clay appreciably rises mainly due to medium and fine dust.

The microaggregate composition of chestnut soils is very resistant to irrigation water. Irrigation conditions demonstrate the trend of increased number of true aggregates, which is more pronounced in sand clay loam that in sand loam soil. The increase of the number of microaggregates in irrigated soils is conditioned by the appearance of labile iron and humic acids forming iron-humic complexes taking part in cementation of microaggregates. The number of microaggregates increases by $3-5 \%$.

The structure and aggregate composition of chestnut soils under irrigation suffers substantial qualitative and quantitative changes: soil lumpiness increases, the number of structural elements of agronomically beneficial size $(10-0.25 \mathrm{~mm})$ drops, the coefficient of structuredness reduces, negligibly drops the water resistance of the aggregates.
The content of water-resistant aggregates larger than 0.25 $\mathrm{mm}$ increases in irrigated soils versus non-irrigated ones by 5 $8 \%$. The largest alteration after irrigation is specific for qualitative indicators of the structure. The density of aggregates of chestnut and dark-chestnut sand loam soils after irrigation increased from $1.34-1.39 \mathrm{~g} / \mathrm{cm}^{3}$ to $1.68-1.74 \mathrm{~g} / \mathrm{cm}^{3}$. The total porosity of aggregates correspondingly decreased from 35 $37 \%$ to $20-23 \%$ of the soil volume. The mechanical strength of the aggregates with the size of 5-1 mm of dark-chestnut soil increased 3-10 times.

Thus, the irrigation leads to controversial behavior. On the one hand, the degradation of the soil structure is obvious: increased lumpiness, density of aggregates, reduced intraaggregate porosity. On the other hand, increased waterresistance and mechanical strength of the aggregates. The degradation of the structure is bound with mechanical impact of heavy machinery on the irrigated soil. The appearance of qualitatively new marks in soil aggregates in conditioned by changed character of soil formation upon irrigation.

TABLE I. IMPACT OF IRRIGATION ON PHYSICAL PROPERTIES OF CHESTNUT SOILS*

\begin{tabular}{|c|c|c|c|c|c|c|}
\hline $\begin{array}{l}\text { granulometric } \\
\text { composition }\end{array}$ & horizon & $\begin{array}{l}\text { sampling depth, } \\
{[\mathrm{cm}]}\end{array}$ & $\begin{array}{l}\text { soil density, } \\
{[\mathrm{g} / \mathrm{cm} 3]}\end{array}$ & $\begin{array}{c}\text { solid phase } \\
\text { density }\end{array}$ & total porosty & $\begin{array}{c}\text { \% of } \\
\text { aeration } \\
\text { volume }\end{array}$ \\
\hline \multirow[t]{7}{*}{ Sand loam } & An & $0-20 / 0-20$ & $1.41 / 1.57$ & $2.59 / 2.58$ & $45.9 / 39.1$ & $29.9 / 7.3$ \\
\hline & B1 & $20-40 / 25-35$ & $1.49 / 1.58$ & $2.61 / 2.61$ & $42.7 / 39.2$ & $27.3 / 9.5$ \\
\hline & B2 & $40-70 / 35-55$ & $1.56 / 1.61$ & $2.64 / 2.62$ & $40.9 / 38.5$ & $23.4 / 11.5$ \\
\hline & B2K & $70-90 / 55-90$ & $1.54 / 1.56$ & $2.66 / 2.63$ & $42.2 / 40.7$ & $26 / 19.3$ \\
\hline & ВСК & $90-133 / 90-128$ & $1.56 / 1.62$ & $2.68 / 2.65$ & $41.8 / 38.9$ & $21.4 / 16.5$ \\
\hline & CK & $\begin{array}{c}133-200 / 128- \\
200\end{array}$ & $160 / 164$ & $2.67 / 2.66$ & $40.1 / 38.3$ & N/a / N/a \\
\hline & & HCP05 & 0.09 & 0.05 & 4 & 4.3 \\
\hline \multirow[t]{7}{*}{ Sand clay loam } & An & $0-21 / 0-22$ & $1.28 / 1.36$ & $2.53 / 2.55$ & $49.4 / 46.7$ & $20.7 / 15.6$ \\
\hline & B1 & $21-41 / 22-37$ & $1.33 / 1.39$ & $2.56 / 2.57$ & $48 / 45.9$ & 23.02 .2018 \\
\hline & B2 & $41-58 / 37-61$ & $1.37 / 1.45$ & $2.6 / 2.59$ & $47.3 / 44$ & $25.8 / 18.4$ \\
\hline & $\mathrm{B} 2 \mathrm{~K}$ & $58-85$ / 61-87 & $1.43 / 1.49$ & $2.65 / 2.62$ & $46 / 43.1$ & $25.5 / 19.5$ \\
\hline & ВСК & $85-134$ / 87-116 & $1.56 / 1.51$ & $2.65 / 2.63$ & $41.1 / 42.6$ & $14.6 / 16.2$ \\
\hline & CK & $\begin{array}{c}134-200 / 116- \\
200\end{array}$ & $1.58 / 1.61$ & $2.65 / 2.67$ & 40.4 / 39.7 & N/a / N/a \\
\hline & & HCP05 & 0.6 & 0.03 & 2.8 & 2.5 \\
\hline
\end{tabular}

The results of our studies testify increased density of irrigated soils. And the densification of soil is detected in upper horizons. To make a quantitative assessment, we have made statistical processing of obtained results and compared the density of irrigated (13 years) and non-irrigated soils (Table 1). The irrigation of chestnut sand loam soils promoted the soil density from 1.40 to $1.57 \mathrm{~g} / \mathrm{cm}^{3}$ in the layer $0-20 \mathrm{~cm}$ and from 1.49 to $1.58 \mathrm{~g} / \mathrm{cm}^{3}$ in the layer $20-40 \mathrm{~cm}$. The densification is observed along the whole 2 -meter depth of soil. Over 13 years, the density of plow layer increased by $0.17 \mathrm{~g} / \mathrm{cm}^{3}$. Annual increment of the soil density amounted to $0.013 \mathrm{~g} / \mathrm{cm}^{3}$.

Long-term irrigation of sand clay loam soils also lead to appreciable increase of the density along the whole depth, though the absolute increase of soil density is slightly lower than in sand loam soils. For instance, in plow horizon $0-20 \mathrm{~cm}$, the soil density increased from 1.28 to $1.36 \mathrm{~g} / \mathrm{cm}^{3}$, in the layer $20-40 \mathrm{~cm}$ by $0.06 \mathrm{~g} / \mathrm{cm}^{3}$. 
Thus, the irrigated soil density exceeded the limits of optimal values for chestnut soils of Kulunda steppe [2, 92]. Despite large initial density, sand loam soils in the conditions of irrigation turned out to be less resistant to the action of water and agricultural machinery. Different impact of irrigation on sand loam and sand clay loam soils is conditioned by larger structural strength of the latter.

The density of solid phase of chestnut soils upon irrigation suffered no changes. The total porosity in the plow layer of sand loam soils has decreased by $6.8 \%$ of the soil volume on average. In the subplow layer $(20-40 \mathrm{~cm})$, the total porosity decreased only by $3.5 \%$. The decrease of the pore dimensions does not exceed $2 \%$. The largest change to the total porosity is observed down to the depth of 50-60 cm. In sand clay loam soils, the irrigation causes lesser-as compared to to sand loam soilschanges to the total porosity In particular, in the plow layer, the total porosity decreased by $2.7 \%$, while in subplow layer by $2.1 \%$. The change of the total porosity is detected down to the depth of $80-85 \mathrm{~cm}$.

A particular importance in the conditions of irrigation is borne by the ratio of pores occupied by water and air. This indicator determines the water retaining capability, microbiological activity and redox conditions. According to the aeration pore volume, the air availability in sand loam soils exceeded the critical values ( $<15 \%$ of volume), in sand clay loam soils it decreased to critical values. The most remarkable changes occurred in plow and subplow layers. Appreciable alteration of aeration porosity are detected down to the depth of $60-80 \mathrm{~cm}$. For example, in the plow layer of sand loam soils, the aeration porosity decreased from 29.9 to $7.9 \%$, in subplow layer from 27.3 to $9.5 \%$, in sand clay loam soils correspondingly from 20.7 to $15.6 \%$ and from 23.2 to $18.0 \%$ of volume.

The impact of irrigation on ratio of pores occupied by water and air in chestnut soils is depicted in Fig. 3.

As a result of 13-year irrigation of chestnut soils of sand loam and sand clay loam type, the volume of pores occupied by echard and chresard has not changed, because the absorption capability of soils remains almost constant. The volume of pores occupied by chresard in sand loam soils in layer $0-20 \mathrm{~cm}$ increased from 11 to $24 \%$ of volume. Along the whole depth, the water content in pores increased 1.5-2 times as compared to non-irrigated soil. In sand clay loam soils, the water content in soils increased by $2-5 \%$. Lesser change of water content, as compared to sand loam soils, is probably conditioned by larger initial water content in pores and smaller change in the ratio of aerated pores and those occupied by water.
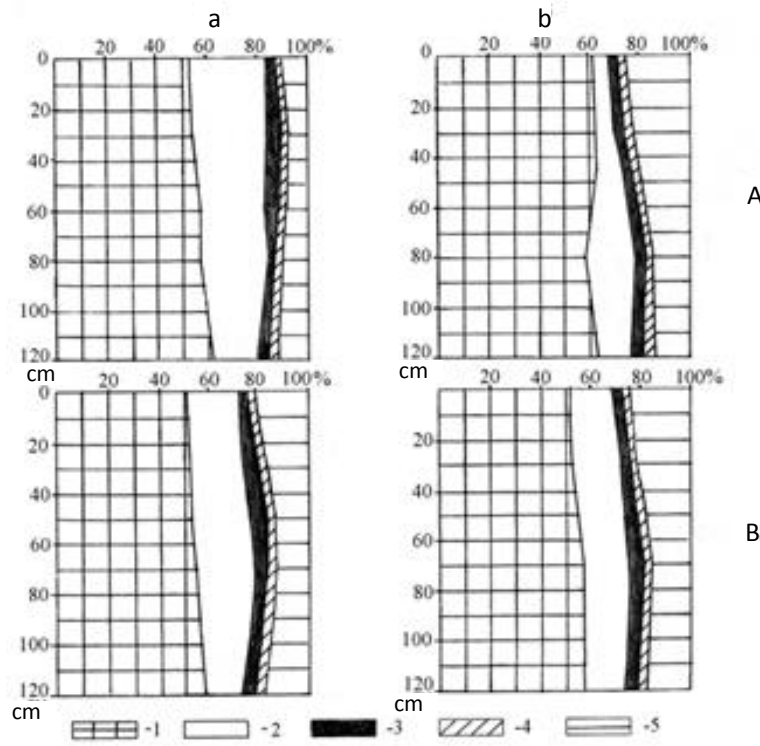

Fig. 3. Differential porosity of chestnut sand loam (A) and sand clay loam (B) soils: a) irrigated; b) non-irrigated. 1) solid phase; 2) aeration porosity; 3) porosity occupied by strongly bound water; 4) porosity occupied by weakly bound water; 5) porosity occupied by labile water

Our studies have shown that in all irrigated soils, as compared to non-irrigated ones, the hydrophysical properties increase. Insignificant changes are typical for echard and chresard. A substantial alteration under irrigation is specific for discontinuous capillary moisture, echard and chresard. We should note that deeper changes to the water retaining capacity are observed in sand loam soils. In sand clay loam soils, the increase in discontinuous capillary moisture and minimum water capacity is not proven statistically. However, the range of active moisture in certain horizons of sand clay loam soils is substantially higher than in non-irrigated ones. In other horizons, there is a tendency to increased range of active moisture.

Fig. 4 shows the changes to hydrophysical properties expressed in the soil volume. 
a

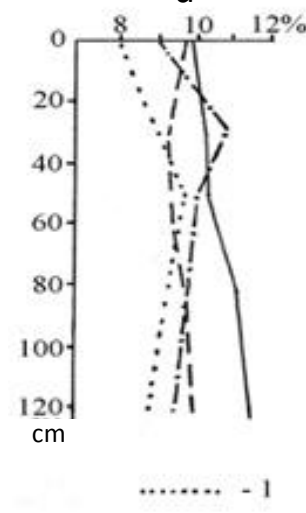

b

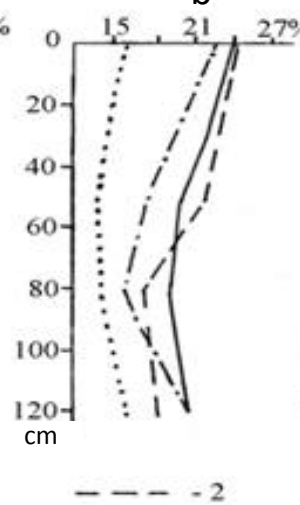

C

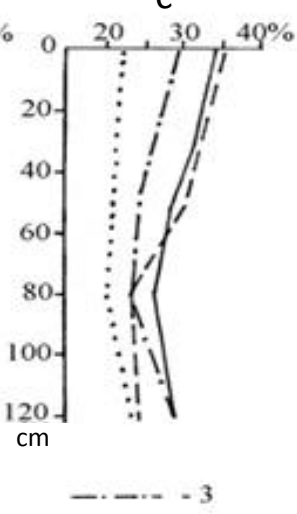

d

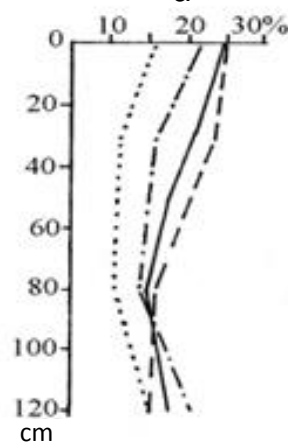

$-4$

Fig. 4. Hydrophysical properties of non-irrigated $(1,3)$ and irrigated $(2,4)$ farm soils: 1,2$)$ sand loam soil; 3, 4) sand clay loam soil

The reserves of different types of moist of irrigated and nonirrigated analogues are given in Table 2. The data tells that the holard and chresard in irrigated soils, as a rule, is slightly higher than those in irrigated soils. The increase of water retaining dsfdsf capability in sand loam soils is typical for layer $0-50 \mathrm{~cm}$. In the layer $50-100 \mathrm{~cm}$, there is no such increase. In sand clay loam soils, the chresard increases along the whole 1-meter depth.

TABLE II. THE CHANGE OF MOISTURE RESERVES IN CHESTNUT SOILS UNDER IRRIGATION (AVERAGED DATE FOR N=18)*

\begin{tabular}{|c|c|c|c|c|c|c|}
\hline \multirow[b]{2}{*}{ Granulometric composition } & \multirow[b]{2}{*}{ Soil layer width $[\mathrm{cm}]$} & \multicolumn{5}{|c|}{ Moisture reserves [mm] } \\
\hline & & echard & chresard & DCM $(0.7$ holard $)$ & holard & irrigation norm \\
\hline \multirow[t]{5}{*}{ Sand loam } & $0-20$ & $11.2 / 14.4$ & $16.5 / 19.4$ & $38.0 / 48.7$ & $54.3 / 69.2$ & $16.3 / 20.5$ \\
\hline & $20-50$ & $18.8 / 21.0$ & $26.2 / 28.4$ & $55.9 / 65.3$ & $79.8 / 92.7$ & $23.9 / 27.4$ \\
\hline & $0-50$ & $30.0 / 35.4$ & $42.7 / 47.8$ & $93.9 / 114$ & $134.1 / 161.9$ & $40.2 / 47.9$ \\
\hline & $50-100$ & $27.2 / 36.8$ & $39.3 / 49.7$ & $88.9 / 87.8$ & $127.0 / 124.7$ & $38.1 / 36.9$ \\
\hline & $0-100$ & $57.2 / 72.2$ & $82.0 / 97.5$ & $182.8 / 201.8$ & $261.1 / 286.6$ & $78.3 / 84.8$ \\
\hline \multirow[t]{5}{*}{ Sand clay loam } & $0-20$ & $12.7 / 15.9$ & $21.1 / 21.5$ & $40.6 / 52.0$ & $58.0 / 74.9$ & $17.4 / 22.5$ \\
\hline & $20-50$ & $24.5 / 21.5$ & $33.0 / 29.0$ & $52.9 / 58.7$ & $75.5 / 83.9$ & $22.6 / 25.2$ \\
\hline & $0-50$ & $37.2 / 37.4$ & $54.1 / 50.5$ & $93.5 / 110.7$ & $133.5 / 158.8$ & $40.0 / 47.7$ \\
\hline & $50-100$ & $38.0 / 40.8$ & $51.5 / 55.1$ & $87.9 / 98.7$ & $125.5 / 141.0$ & $37.6 / 42.3$ \\
\hline & $0-100$ & $75.2 / 78.2$ & $105.6 / 105.6$ & $181.4 / 209.4$ & $259.0 / 299.8$ & $77.6 / 90.4$ \\
\hline
\end{tabular}

a. * numerator is for non-irrigated, denominator is for irrigated farm soils

For instance, after 13 years of irrigation of chestnut sand loam soils, the water retaining capability in the layer $0-20 \mathrm{~cm}$ increased from 54 to $69 \mathrm{~mm}$, in layer $20-50 \mathrm{~cm}$ from 80 to 93 $\mathrm{mm}$ and in layer $0-50 \mathrm{~cm}$ from 134 to $162 \mathrm{~mm}$. For layer $50-$ $100 \mathrm{~cm}$ no such increase was established. In the irrigated sand clay loam soils, the water retaining capability in layer $0-20 \mathrm{~cm}$ increased by $17 \mathrm{~mm}$, in layer $20-50 \mathrm{~cm}$ by $8 \mathrm{~mm}$, in layer $0-50$ $\mathrm{cm}$ by $25 \mathrm{~mm}$ and in layer $50-100 \mathrm{~cm}$ by $16 \mathrm{~mm}$. In general, for layer $0-100 \mathrm{~cm}$, the increase amounted to $41 \mathrm{~mm}$.

In irrigated (for 13 years) sand loam soils, the chresard in layer 0-20 cm increased, as compared to non-irrigated ones, by $12 \mathrm{~mm}$, in layer $20-50 \mathrm{~cm}$ by $11 \mathrm{~mm}$, in layer $0-50 \mathrm{~cm}$ by 23 $\mathrm{mm}$. In layer $50-100 \mathrm{~cm}$, the chresard decreased by $13 \mathrm{~mm}$. In total, for 1-meter layer, the increase of chresard amounted to only $10 \mathrm{~mm}$. In sand clay loam irrigated soils, the average increment of chresard for layers $0-50$ and 50-100 $\mathrm{cm}$ amounted to 29 and $12 \mathrm{~mm}$, for layer $0-100 \mathrm{~cm} 41 \mathrm{~mm}$.

The study results show that in irrigated sand loam soils increased echard. The increase for layer $0-50 \mathrm{~cm}$ amounted to $5 \mathrm{~mm}$, for layer $50-100 \mathrm{~cm} 10 \mathrm{~mm}$, for layer $0-100 \mathrm{~cm} 15 \mathrm{~mm}$. In sand clay loam irrigated soils in the first $50 \mathrm{~cm}$, we discovered decreased echard and similar, in terms of absolute value, increase of it in the remaining $50 \mathrm{~cm}$. The total echard in layer $0-100 \mathrm{~cm}$ remained the same.

Thus, the irrigation of chestnut soil of the massif has different impact on hydrophysical properties. The holard in sand loam soils in layer $0-100 \mathrm{~cm}$ increased by $25 \mathrm{~mm}$, while in sand clay loam soils by $41 \mathrm{~mm}$. The chresard increased respectively by 10 and $41 \mathrm{~mm}$. The echard in sand loam soils 
increased by $15 \mathrm{~mm}$, in sand clay loam soils it remained the same.

Water resistance of soils is one of the most important indicators in ameliorative evaluation of soils to determine the regimes and norms of irrigation, watering methods and techniques. It mainly determines the depth of wetting. Among all hydrophysical indicators, the water permeability changes the most in time and along the soil surface. Average permeability values of irrigated and non-irrigated soils of the massif are given in Table 3. After 13 years of irrigation of chestnut sand loam soils, the water permeability over 1 hour of observations decreased from 108.8 to $94.6 \mathrm{~mm} / \mathrm{h}$. This is conditioned by increased density. In the sand clay loam irrigated soils over the first hour, the water permeability turned out to be even higher that that for non-irrigated soils. However,already in the second hour of observations, in the irrigated sand loam soils the water permeability decreases 1.6 times, in sand clay loam soils the figure is 1.4 times. By the sixth hour of observation, the water permeability from the surface to sand loam and sand clay loam soils decreased 1.8 and 1.9 times, respectively.

TABLE III. WATER PERMEABILITY OF CHESTNUT SOILS (AVERAGED VALUES FOR $=18$ ), $M M / H$ AT T $=10^{\circ} \mathrm{C}$

\begin{tabular}{|c|c|c|c|c|c|}
\hline \multirow{2}{*}{ Granulometric composition } & \multicolumn{5}{|c|}{ Observation Time [min] } \\
\hline & 30 & 60 & 120 & 180 & 240 \\
\hline Sand loam* & $117.9 / 130.8$ & $\begin{array}{c}108.8 \\
/ \\
94.6\end{array}$ & $\begin{array}{c}93.3 \\
/ \\
58.8\end{array}$ & $\begin{array}{c}87.1 \\
/ \\
56.3\end{array}$ & $\begin{array}{c}80.4 \\
/ \\
52.5\end{array}$ \\
\hline HCP05 & 12.5 & 12.5 & 13.3 & 13.3 & 13.3 \\
\hline Sand clay loam & $105.4 / 117.5$ & $\begin{array}{c}97 / \\
110.5\end{array}$ & $\begin{array}{c}76.7 \\
/ \\
53.3\end{array}$ & $\begin{array}{c}70 / \\
48.3\end{array}$ & $\begin{array}{c}68.3 \\
/ \\
42.5\end{array}$ \\
\hline HCP05 & 14.6 & 16.7 & 12.5 & 10.4 & 8.8 \\
\hline
\end{tabular}

Ultimately, the water permeability of the massif is quite controversial and can differ 2-3 times depending on the cultivated crop, agromachinery and other factors. Despite the differences, the water permeability can be an assessment indicator of ameliorative condition. The water perme-ability of soils indicates the appearance of degradation changes due to their irrigation.

\section{CONCLUSION AND DISCUSSION}

Irrigation causes the pedologic and physical conditions of farm soils to become less favora-ble for agricultural crops: it increases the number of microagregates, waterproof aggregates larger than $0.25 \mathrm{~mm}$, and raises their mechanical strength and water resistance, increases the soil density, reduces total porosity and water capacity, increases holard and chresard, reduces water permeability indicating the degradation processes in irrigated farm soils.

The results many times were discussed on pan-Russian and international scientific and practical forums: III congress of Dokuchaev society of soil scientists (Suzdal, 2000), International scientific and practical conference Modern problems and achievements of agrarian science in cattle breeding and crop cultivation (Barnaul, 2003), V Meeting of Dokuchaev Association of of Soil Scientists (Rostov on Don, 2008), VI Meeting of Dokuchaev Association of of Soil Scientists (Petrozavodsk, 2012).

\section{References}

[1] V.A. Baranovskaya, V.I. Azovtsev, "Impact of irrigation on modern soil formation", Proc. X Inter. Congr. Soil Sci, Moscow, 1974. pp. 132-136.

[2] A.G. Bondarev, "Alteration of physical properties and hydrological regime of irrigated soils", Problems of soil science, Moscow, 1982, pp. $137-142$.

[3] L.M. Burlakova, L.M. Tatarintsev, N.K.Glushkova, "Impact of irrigation on certain properties of dark-chestnut soils of Kulunda steppe", Proc. Sci. \& Prod. Conf. Soil, Agrochemicians and Farmers of Urals and Volga region, Ufa, 1988, pp.135-136 [Scientific principles and practical methods for increaseing the soil fertility of Urals and Volga region, 19880]

[4] L.P. Kozleneeva, "Impact of irrigation by subsaline water on properties of chernozems of Baraba", Extended abstract of Cand. Sci. (Biol.), Novosibirsk, 1988, p. 16.

[5] A.E. Kudryavtsev, "Impact of irrigation on physical condition of chestnut and chernozemic soils in Altai Krai", Thesis of Cand. Sci. (Agri.), Barnaul, 1995, p. 170.

[6] "Kulunda steppe and issues of its amelioration", Novosibirsk: Nauka, 1972, p. 505.

[7] P.S. Lozovitskiy "Impact of long-term irrigation by subsaline water on the fertility indicators of south chernozems", Bulletin of Agroscience, 1996, No. 3, pp. 21-26.

[8] V.E. Prikhodko, A.N. Galibin, I.V. Ivanov, "Impact of irrigationon dark chestnut soils of Syrtov plain in trans-Volga region under irrigation", Soil science, 1986, No.5, pp.76-86

[9] E.V. Strugaleva, "Salinity regime of AOS soils and ways of its regulation", Extended abstract of Cand. Sci. (Agri.), Irkutsk, 1963, p. 16.

[10] E.V. Strugaleva, K.Y. Fesko, I.T. Trofimov et al, "Impact of irrigation on properties of AOS soils", Proc. Altai Agroinst., Vol. 180. Barnaul, 1976, pp. 91-96.

[11] L.M. Tatarintsev, V.L. Tatarintsev, T.I. Pushkareva, N.Yu. Kablova, "Irrigation of Kulunda steppe: ameliorative condition of soils, problem of 
yield improvement", Amelioration and water services, 2001, No. 4, pp. 36-38.

[12] V.L. Tatarintsev, L.M. Tatarintsev, M.N. Kostritsina, S.I. Eshchenko, "Models of ameliorative condition of farm soils using granulometry datam", Bulletin of Altai State Agrarian University, 2017, No. 7 (153), pp. $72-78$.
[13] L.D. Baver, "Soil physics", New York, 1956, p. 489.

[14] G. Sposito, "The Thermodynamics of soil solutions", Oxford: Clarendon Press, 1981, p. 238. 